\title{
ATIVIDADES RECREATIVAS COMO PARTE DA METODOLOGIA DIDÁTICA NO ENSINO SUPERIOR APLICADAS ÀS DISCIPLINAS MECÂNICA DOS FLUIDOS E HIDRÁULICA
}

Anderson Ravikdos Santos - anderson.ravik@gmail.com

Emmanuel Kennedy da Costa Teixeira - emmanuel.teixeira@ufsj.edu.br

Universidade Federal de São João del-Rei - Campus Alto Paraopeba, Departamento de

Tecnologia em Engenharia Civil, Computação e Humanidades

Rodovia MG-443, km 7 - Fazenda do Cadete

36420-000 - Ouro Branco - Minas Gerais

Resumo: Atividades recreativas fazem parte de uma prática de ensino prazerosa e são um importante instrumento de socialização e aprendizagem na sala de aula, porém pouco usuais no âmbito universitário. O constante uso do modelo tradicional de educação impede que a ação do professor dentro da sala de aula se torne mais atrativa e motivante neste meio. $O$ presente trabalho apresenta três atividades recreativas desenvolvidas para serem aplicadas nas aulas das disciplinas Mecânica dos Fluidos e Hidráulica, do curso de Engenharia Civil da Universidades Federal de São João del-Rei. Por meio de um questionário, os alunos participantes puderam avaliar critérios quanto à aceitação, aplicação, eficiência e objetivos envolvendo este tipo de atividade como método de ensino. Os resultados mostram que é possível associar o processo de ensino-aprendizagem nas universidades às atividades recreativas, propiciando conhecimento de forma lúdica e uma aprendizagem expressiva para os alunos.

Palavras-chave: Método de ensino. Metodologia ativa. Atividades recreativas.

\section{INTRODUÇÃ̃}

As atividades recreativas constituem uma prazerosa prática de ensino em que os alunos podem participar da aula de forma descontraída. Elas podem se mostrar como um instrumento importante de socialização e aprendizagem na sala de aula, além de promover a discussão do assunto ministrado de forma mais atraente. Entretanto, percebe-se que seu uso é bem mais presente, e com maior destaque, na educação infantil ou nas séries iniciais da educação básica, embora se mostre como ferramenta importante na construção do saber do indivíduo, tanto durante a infância quanto na fase adulta.

No âmbito universitário, tais atividades são tidas muitas vezes como incompatíveis. Isso se deve principalmente ao constante uso do Modelo tradicional de educação, baseado no professor como o dono do saber e centro do processo de ensino e nos alunos como agentes passivos perante a repetição e memorização dos conteúdos, sendo estes descritos como verdades absolutas (SCHRAMM, 2001). Perde-se, assim, a chance de tornar a ação do professor dentro da sala de aula mais atrativa e motivante, tanto para o aluno quanto para si próprio.

O prazer, satisfação e descontração que acredita-se serem ofertados pela prática das atividades recreativas podem contribuir também para sanar a ansiedade dos alunos em vésperas de prova. É sabido que ansiedade demais danifica o raciocínio, enfraquece a 
concentração, o foco e causa perda de memória. Por mais que estudem muito, alguns estudantes ainda se sentem inseguros na hora de realizar exames que avaliem seu preparo, disciplina e raciocínio. Hill e Wigfield (1984) propõem a definição de ansiedade de prova: trata-se de um "sentimento desagradável ou estado emocional que tem componentes fisiológicos e comportamentais, e que é experimentado por ocasião de testes formais ou de outras avaliações".

Mandler e Sarason (1952) identificaram empiricamente, através de uma escala específica, a existência de alunos com alto nível e baixo nível de ansiedade e perceberam que estes alunos obtiveram resultados inversamente proporcionais a este nível em testes de inteligência. Ou seja, muitos alunos não conseguem mostrar nessas situações o que tinham aprendido ou o que sabem, prejudicados pela ansiedade.

A motivação para realizar este trabalho adveio do enfrentamento de uma problemática: o baixo rendimento de alguns alunos, ocasionando em alguns casos sua reprovação, nas avaliações das disciplinas Mecânica dos Fluidos e Hidráulica, que figuram como disciplinas obrigatórias na grade curricular do curso de Engenharia Civil da Universidade Federal de São João del-Rei, Campus Alto Paraopeba (UFSJ/CAP). O problema em questão apresenta múltiplos fatores, como a má formação dos alunos referente aos conceitos prévios necessários à compreensão das disciplinas e a grande quantidade de matéria, principalmente teórica, envolvendo-as. Destaca-se um outro fator limitante constatado, no que diz respeito ao rendimento dos estudantes: o perceptível aumento da ansiedade e nervosismo em véspera e durante as avaliações.

A fim de diminuir esta insegurança e promover aulas de conteúdos teóricos mais dinâmicas, com participação ativa dos alunos, foi sugerida a utilização de atividades recreativas como parte da metodologia didática a ser utilizada pelo professor. Nesse contexto, o presente trabalho tem como proposta o desenvolvimento de atividades recreativas a serem aplicadas nas disciplinas Mecânica dos Fluidos e Hidráulica, objetivando responder a seguinte pergunta: as atividades recreativas podem ser utilizadas como um método didático eficiente no ensino superior?

\section{METODOLOGIA}

O presente trabalho foi realizado com foco nas aulas das disciplinas Mecânica dos Fluidos e Hidráulica, pertencentes à grade do curso de Engenharia Civil, do $4^{\circ}$ e $5^{\circ}$ período respectivamente, da UFSJ/CAP. Participaram das atividades os alunos que cursavam Hidráulica no primeiro semestre de 2016 e os que cursavam Mecânica dos Fluidos e Hidráulica no segundo semestre do mesmo ano.

Como instrumento de coleta de dados foi utilizado, ao fim de cada semestre, um formulário composto por cinco questões objetivas, referentes à aceitação, aplicação, eficiência e os objetivos envolvendo as atividades recreativas como método de aprendizagem no ensino superior. Nele também havia uma questão aberta para apresentação de sugestões, críticas e elogios que pudessem oferecer um direcionamento dos pontos a serem melhorados e aperfeiçoados. O preenchimento deste formulário ocorreu de forma anônima pelos participantes.

Escolheu-se a utilização de um questionário por este apresentar vantagens, como: atender um maior número de pessoas em menor tempo, poder garantir o anonimato nas respostas e não gerar influência de ideias ou opiniões entre pesquisador e sujeito da pesquisa. Entretanto, utilizar um questionário deste tipo também pode apresentar algumas desvantagens, como não oferecer garantia de comprometimento pleno do sujeito da pesquisa com o estudo, resultando em respostas incompletas ou não respondidas (MARCONI e LAKATOS, 2003). 
As atividades recreativas aqui citadas foram criadas pelos próprios autores do trabalho, tais como suas regras e funcionamento. Coube ao professor produzir e adaptar os conteúdos da disciplina a cada uma delas. Os instrumentos utilizados para desenvolver as atividades, os chamados estimulantes visuais, também foram confeccionados por um dos autores.

Todas as atividades desenvolvidas fomentaram o trabalho em grupo e a competitividade saudável entre os alunos, sendo que ao fim de cada uma delas um ou mais grupos terminaram vencedores. Coube ao professor definir se haveria alguma premiação para estes últimos (pontos extras, prêmios simbólicos, etc.), sempre de forma consensual com a turma e prévio aviso. Este tipo de iniciativa, se bem utilizada, pode funcionar como um incentivo à participação mais atenciosa e ativa dos estudantes.

As atividades foram realizadas durante o horário normal de aula, sempre contando com a participação direta do professor, a fim de que ele pudesse se familiarizar com os procedimentos a serem adotados em cada uma delas. No primeiro semestre de 2016 foram reservadas duas aulas de Hidráulica para aplicação destas atividades, enquanto no segundo semestre do mesmo ano foram aplicadas duas atividades em Hidráulica e uma atividade em Mecânica dos Fluidos.

Neste contexto, foram desenvolvidas três atividades recreativas diferentes, nomeadas de "Enchendo os reservatórios", "Responde ou Passa" e "Caçada Pokémon".

\subsection{Enchendo os reservatórios}

A atividade "Enchendo os reservatórios" tratava-se de um Verdadeiro ou Falso. O professor lia uma questão objetiva por vez e dava um minuto para que os grupos pudessem discutir sobre a veracidade ou falsidade da afirmação. Não eram permitidas consultas ao próprio material acadêmico ou de outras fontes. Terminado o tempo de discussão, e ao sinal do mediador da atividade, um representante de cada grupo erguia a placa contendo "V" ou "F" de acordo com a resposta escolhida.

Os grupos que acertaram ganharam um nível de água em seu reservatório, enquanto os grupos que erraram, perderam um nível de água, caso o reservatório não estivesse vazio. $\mathrm{O}$ reservatório de cada grupo era da cor correspondente às suas placas de "V" ou "F". Foi declarado vencedor o grupo que conseguiu encher por completo o seu reservatório primeiro, sendo necessário para isso conseguir oito níveis de água. Após o professor revelar a resposta correta, abria-se uma breve discussão a respeito da questão, a fim de sanar qualquer dúvida dos grupos. A Figura 1 mostra as placas utilizadas para responder às perguntas enquanto a Figura 2 aponta como ficou um reservatório cheio ao final da atividade.

\subsection{Responde ou passa}

A atividade "Responde ou passa" tratava-se de um quiz de perguntas discursivas. Para esta atividade, utilizou-se como estimulante visual um painel no qual eram encaixados círculos numerados de 1 a 31. Inicialmente todos os círculos eram embaralhados e encaixados aleatoriamente. $\mathrm{O}$ lado dos círculos que ficava à mostra nesta fase inicial era azul, assim como o painel. No verso, cada círculo apresentava uma cor diferente podendo ser branco, vermelho, preto ou amarelo, como pode ser visto na Figura 3. 
Figura 1 - Placas de V ou F: estimulantes

visuais utilizados para a atividade

recreativa "Enchendo os Reservatórios".

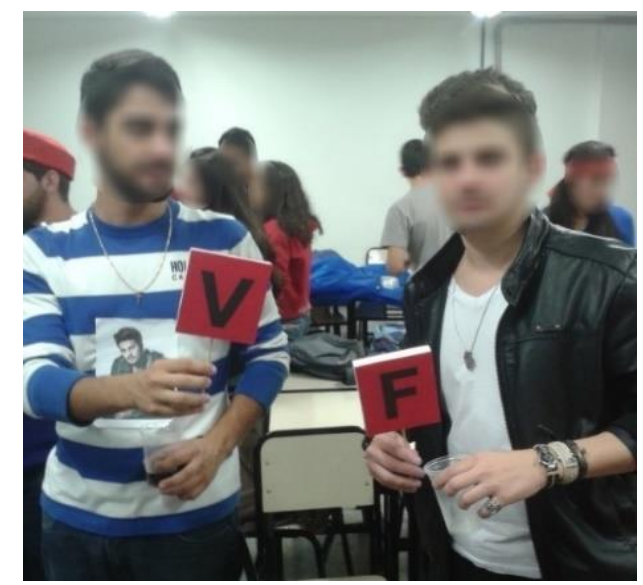

Fonte: Fotos dos autores

Figura 2 - Reservatório cheio ao final da atividade recreativa "Enchendo os Reservatórios".

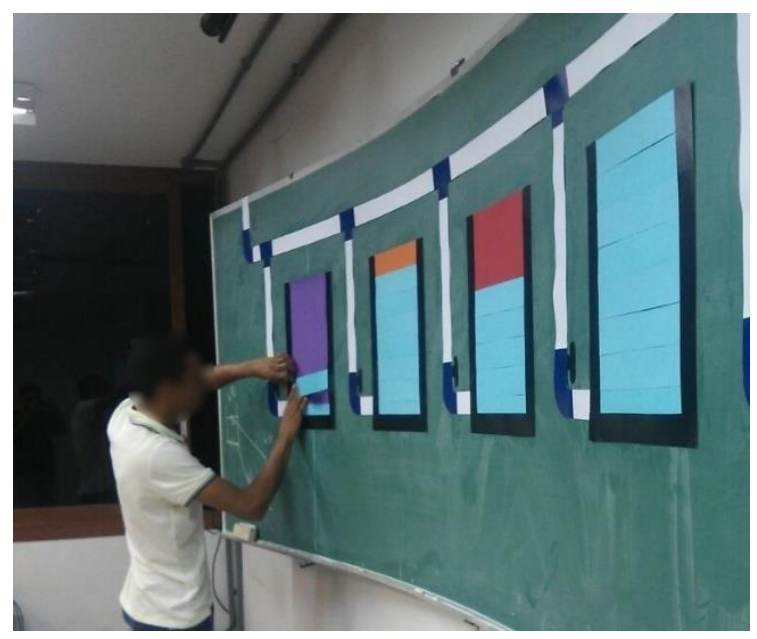

Fonte: Fotos dos autores

Figura 3 - Painel utilizado como estimulante visual ao final da atividade "Responde ou passa".

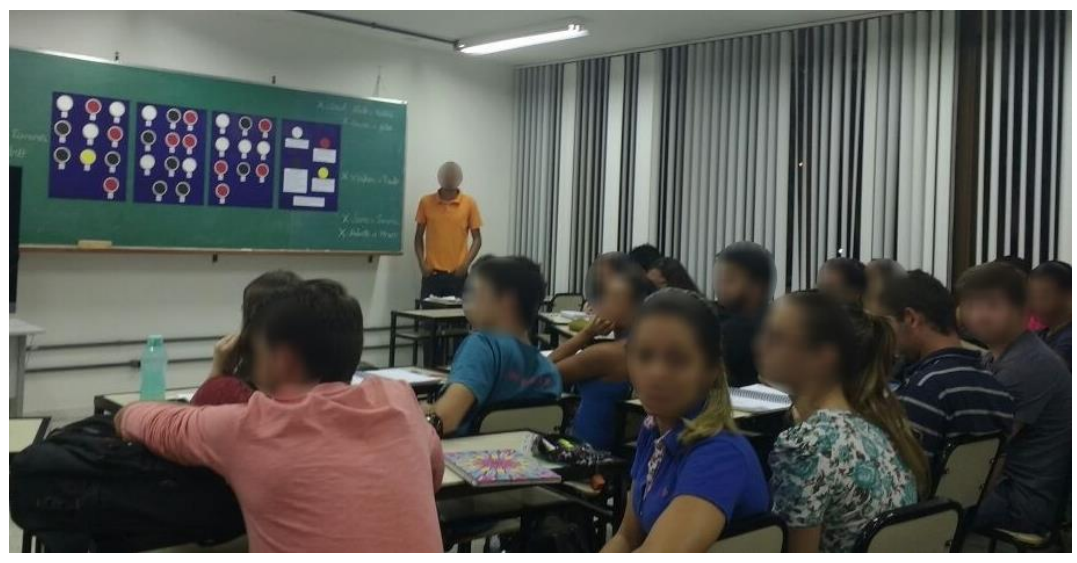

Fonte: Fotos dos autores 
A sala era dividida em duplas e a cada rodada o mediador sorteava uma delas. Esta, por sua vez, escolhia um número no painel e era revelada a cor do círculo escolhido. O professor então fazia uma pergunta referente a algum tema discutido durante as aulas e a dupla tinha dois minutos para discutir entre si sobre resposta. Nesta atividade era permitido consultar anotações do caderno. A partir daí, poderiam ocorrer diferentes situações de acordo com a cor retirada anteriormente pela dupla.

Caso o círculo fosse branco e a dupla respondesse à pergunta corretamente, ela seguia no jogo normalmente. Caso o círculo fosse vermelho e a dupla respondesse à pergunta corretamente, além de continuar no jogo a dupla poderia eliminar uma dupla concorrente que já tivesse acertado pelo menos uma questão anteriormente. Se o círculo escolhido fosse preto, a dupla teria a opção de não responder a pergunta depois de ouvi-la e passar a vez. E por último, caso o círculo fosse amarelo e dupla respondesse à pergunta corretamente, ela poderia trazer de volta ao jogo uma dupla eliminada. Em qualquer um dos casos, errar a resposta da pergunta acarretava na eliminação da dupla.

Ao final da atividade, depois de não haver mais duplas a serem sorteadas, eram declaradas vencedoras todas as duplas que não haviam sido eliminadas durante a atividade.

\subsection{Caçada Pokemón}

A atividade "Caçada Pokémon" se tratava de um quiz de múltipla escolha e foi desenvolvida aproveitando-se do sucesso do aplicativo gratuito "Pokémon Go" lançado em agosto de 2016, no Brasil, que virou febre entre os jovens. Seus estimulantes visuais incluíram um painel de coordenadas onde estavam localizadas 15 "pokebolas", como mostra a Figura 4.

Figura 4 - Painel utilizado como estimulante visual durante a atividade "Caçada Pokémon".

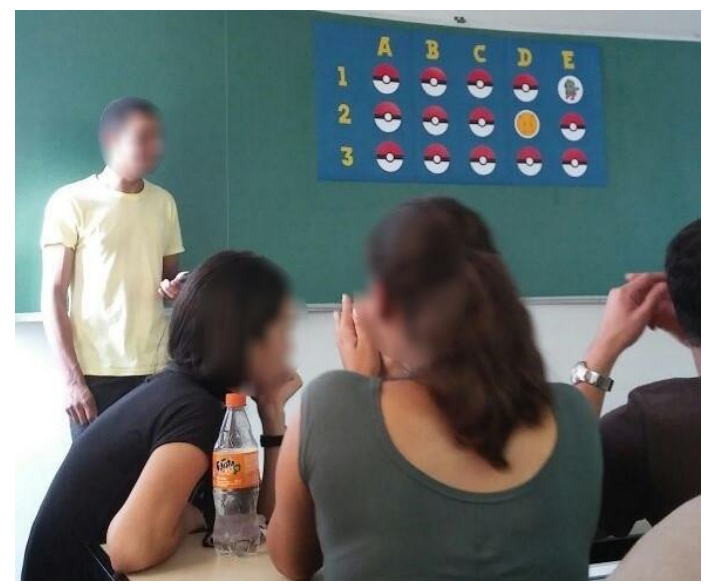

Fonte: Fotos dos autores

A turma era dividida em equipes, numeradas para posterior sorteio, e cada equipe recebia uma folha de respostas contendo o número das questões e para cada uma delas as alternativas de "A" a "D". O mediador então, sorteava uma equipe e esta escolhia uma "pokebola" do painel, utilizando suas coordenadas. O mediador apresentava o "Pokémon" contido nela, assim como sua respectiva pontuação extra, que variava de $-3 a+3$.

Feito isso, era apresentada para toda turma, por meio de uma apresentação de slides, uma questão objetiva com quatro alternativas de resposta. As equipes tinham um minuto para discutir sobre qual das alternativas era a correta, devendo marcar a escolhida na folha de 
resposta. Passado este tempo, a projeção era interrompida, uma nova equipe era sorteada e repetia-se o processo até que todos os "Pokémons" tivessem sido revelados, um por cada equipe.

Finalizadas as questões, as equipes trocavam as folhas de resposta entre si para a correção das questões, juntamente com o professor, que aproveitava o momento para propor discussões a respeito das questões. Terminada a correção, a pontuação conseguida pela equipe, sendo que cada acerto valia 1 ponto, era acrescida da pontuação extra advinda do "Pokémon" encontrado no painel.

A equipe ou equipes com maior pontuação total eram consideradas vencedoras. A Figura 5 apresenta o painel depois de terem sido descobertos todos os "Pokémons", ao final da atividade. Também podem ser vistos os autores do trabalho conduzindo a atividade.

Figura 5 - Painel ao final da atividade "Caçada Pokémon”.

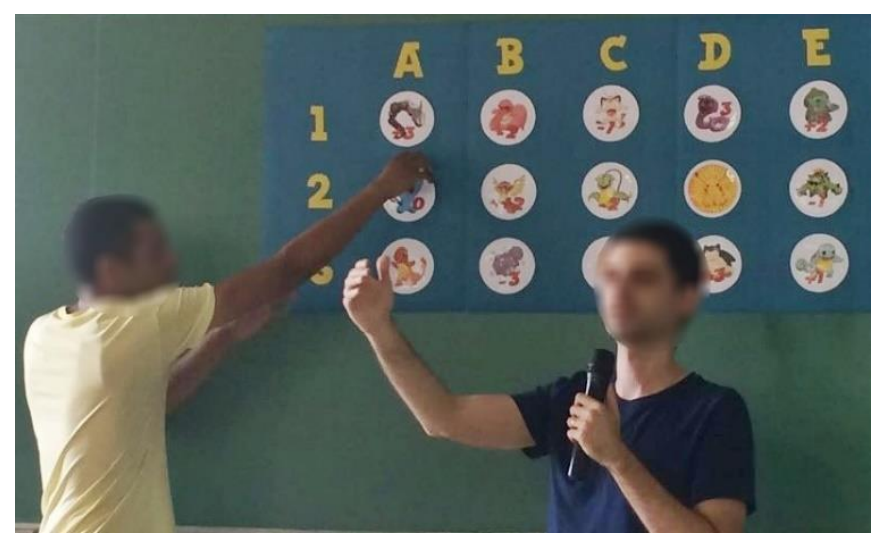

Fonte: Fotos dos autores

\section{RESULTADOS E DISCUSSÃO}

O questionário, composto por seis questões, foi aplicado no primeiro e segundo semestre de 2016 e contou com a contribuição de 90 alunos que participaram de pelo menos uma das atividades recreativas citadas. Destes alunos, 32 cursaram Hidráulica no primeiro semestre, enquanto 34 cursaram no segundo. Ainda houve a participação de 24 alunos que cursaram Mecânica dos Fluidos no segundo semestre. A última questão, que não era de preenchimento obrigatório, permitia que o aluno, se desejasse, deixasse sua sugestão ou crítica, contribuindo para o desenvolvimento e aprimoramento do projeto.

Analisando os resultados da primeira questão, percebe-se que quase todos os alunos que responderam ao questionário acreditavam que as atividades recreativas podem contribuir no processo de ensino-aprendizagem também no ensino superior, sendo que somente quatro dos 90 participantes ficaram em dúvida a respeito desta contribuição, enquanto nenhum dos participantes negou esta possibilidade, como mostra a Figura 6. 


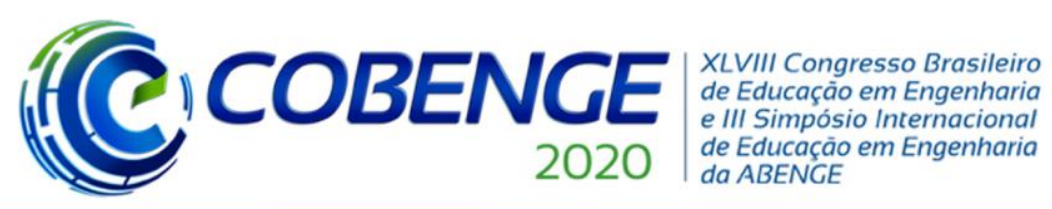

"Os desafios para formar hoje o engenheiro do amanhã"
$\mathrm{O}$ a $\mathrm{O3}$ de dezembro Evento On-line

Figura 6 - Respostas à Questão 01

Atividades recreativas são usualmente utilizadas como metodologia de ensino nos anos iniciais, ensino fundamental e médio. Você acredita que estas atividades podem contribuir no processo de ensino-aprendizagem também no ensino superior?

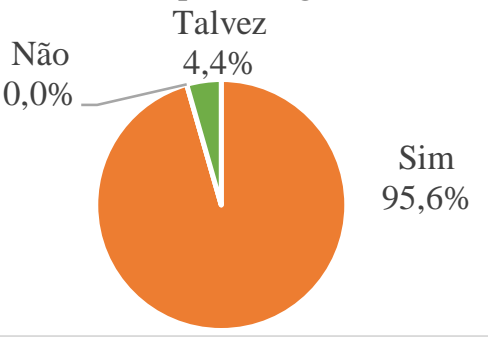

- Sim

- Não

- Talvez

Fonte: Autoria própria

O número de duvidosos, que escolheram "talvez" como resposta, aumentou para seis na segunda questão e sete na terceira. Entretanto, a grande maioria também acreditava que estas atividades podem ser consideradas um meio de aprendizagem e ainda que elas podem acarretar numa melhoria na qualidade das aulas, como pode ser visto na Figura 7 e Figura 8. Novamente, nenhum dos alunos negou as indagações.

Figura 7 - Respostas à Questão 02

Você acredita que atividades recreativas podem ser consideradas um meio de aprendizagem?

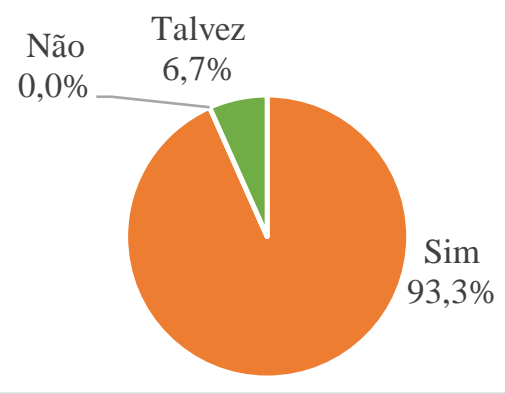

Fonte: Autoria própria

Figura 8 - Respostas à Questão 03

Você acredita que a utilização deste tipo de atividade pode acarretar numa melhoria na qualidade das aulas?

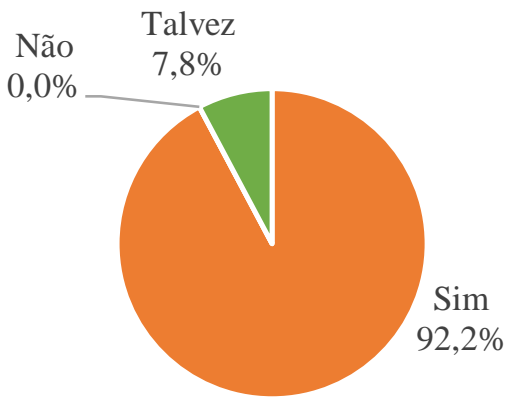


Na Figura 10, muitos participantes também apontaram que com as atividades puderam adquirir novos conhecimentos sem estresse e sociabilizar com os colegas. A opção "Exercitou sua capacidade de memorização" se mostrou como a ação menos realizada, tendo sido elencada por $63,3 \%$ dos alunos; o que demonstra uma descrença por parte do restante a respeito da contribuição das atividades recreativas para a memorização dos conteúdos apresentados, principalmente teóricos.

Alguns comentários deixados na sexta e última questão ajudaram a confirmar a boa aceitação dos alunos do ensino superior diante das atividades recreativas desenvolvidas e sua efetiva contribuição no processo de ensino-aprendizagem. Seguem abaixo alguns destes comentários.

"Seria interessante a realização de uma atividade, pelo menos, antes de cada prova já que é feita uma revisão do conteúdo".

"Gostaria de parabenizar pela iniciativa das aulas, ela contribuiu bastante para o alívio do estresse antes da prova além de contribuir para o estudo".

"Trata-se de um excelente projeto. Principalmente por envolver uma disciplina que os alunos já começam com um grande medo e receio. Se todos os envolvidos souberem aproveitar as mudanças, fez e continuará contribuindo muito".

"Parabéns pela iniciativa! Acredito que as atividades recreativas deram uma leveza maior à matéria e tiraram um pouco do estresse pré prova. Tomara que dê certo e mais professores comecem a praticar".

"Foram as melhores aulas que eu tive até hoje na graduação, estão de parabéns. Continuem levando esse projeto 'pras' salas de aula".

"Projeto muito legal, outra forma de aprendizagem que fez a turma se descontrair e tirar eventuais dúvidas que ainda tinha. Parabéns!"

"Parabéns pela iniciativa, achei super válidas as atividades, realmente houve descontração e aprendizagem”.

"Aprovei o projeto e acredito que seria válido espalhar a ideia para outras disciplinas que os alunos também têm mais dificuldades".

\section{CONSIDERAÇÕES FINAIS}

O presente trabalho partiu do pressuposto de que é possível associar o processo de ensino-aprendizagem às atividades recreativas, com o intuito de propiciar conhecimento de forma lúdica com uma aprendizagem significativa para os alunos. Constatou-se que a inserção deste tipo de atividade como uma estratégia de ensino e que a postura que o professor assume na utilização deste recurso no ensino superior promovem uma aula mais atrativa que consequentemente instiga maior participação dos alunos.

Acredita-se que a comunidade acadêmica pode se aproveitar do estudo aqui desenvolvido, abrindo espaço para a discussão da importância das atividades recreativas e sua contribuição no processo de ensino-aprendizagem. Acredita-se ainda que os objetivos propostos foram alcançados e espera-se que os resultados obtidos cooperem em tornar o processo de ensino-aprendizagem cada vez mais lúdico e cada vez menos tradicional, principalmente nas disciplinas onde as atividades foram apresentadas.

Por fim, o presente trabalho possibilitou o debate e a reflexão a respeito do processo de ensino-aprendizagem nas universidades, de forma a construir um contexto educativo caracterizado pela participação, qualidade, diálogo e interação por meio das atividades recreativas. 
"Os desafios para formar hoje o engenheiro do amanhã"

\title{
Agradecimentos
}

$\mathrm{O}$ primeiro autor agradece o segundo autor e orientador deste trabalho pelo apoio e incentivo durante a graduação e pela fonte de inspiração que sempre foi dentro e fora da sala de aula.

\section{REFERÊNCIAS}

HILL, K. T.; WIGFIELD, A. Test Anxiety: A Major Educational Problem and What Can Be Done About It. The Elementary School Journal, 85(1): 105-126, 1984.

MANDLER, G.; SARASON, S. B. A Study of Anxiety and Learning. Journal of Abnormal and Social Psychology, 47: 166-173, 1952.

MARCONI, M.A.; LAKATOS, E. M. Técnicas da pesquisa. 5. ed. São Paulo: Atlas, 2003.

SCHRAMM, M.L.K. As tendências pedagógicas e o ensino-aprendizagem da arte. In: PILLOTTO, S.S.D.; SCHRAMM, M.L.K. (Org.). Reflexões sobre o ensino das artes. Joinville: Ed. Univille, 2001. v. 1, p. 20-35.

\section{RECREATIONAL ACTIVITIES AS PART OF THE DIDATIC METHODOLOGY ON HIGHER EDUCATION APPLIED TO THE FLUID MECHANICS AND HYDRAULICS COURSE}

\begin{abstract}
Recreational activities are part of a joyful teaching practice and also an important tool in classes' socializing and learning process, but they are unusual in college context. The continual use of a traditional pattern of education precludes that the action of the teacher within the classroom becomes more attractive and motivating. This article presents three recreational activities developed to be applied in Fluid Mechanics and Hydraulics' courses in the Civil Engineering major at São João del-Rei Federal University. Through a questionnaire, the participating students could evaluate the criteria about acceptance, application, effectiveness and the goals involving this kind of activity as a teaching method. The results show that it's possible to associate the teaching and learning process in college to recreational activities as it provides knowledge in a ludic way and gives students meaningful learning.
\end{abstract}

Keywords: Recreational Activities. Teaching method. Active Methodology. 